\title{
Correlation of internal carotid artery diameter and carotid flow with asymmetry of the circle of Willis
}

Te-Chang $\mathrm{Wu}^{1,2,3^{*}} \mathbb{D}$, Tai-Yuan Chen ${ }^{3,4} \mathbb{E}$, Ching-Chung Ko ${ }^{3,5} \mathbb{D}$, Jeon-Hor Chen ${ }^{6,7} \mathbb{D}$ and Ching-Po Lin ${ }^{1,8} \mathbb{D}$

\begin{abstract}
Background: The purpose of this study was to clarify the effect of asymmetric COW variants on carotid flow changes, and proposed an easy estimate of the representative carotid flow volume for accurate numerical simulation.
\end{abstract}

Methods: A total of 210 healthy adults receiving magnetic resonance angiography and carotid duplex sonography were included. Three anterior cerebral artery asymmetry (AA) groups were defined based on the diameter ratio difference (DRD) of bilateral A1 segments: AA1 group, one-side A1 aplasia; AA2, A1 DRD $\geq 50 \%$; AA3, A1 DRD between 10 and 50\%. Similarly, 3 posterior communicating artery (PcomA) asymmetry (PA) groups were defined: PA1 group, one fetal-origin posterior cerebral artery and absent contralateral PcomA; PA2, PcomA DRD $\geq 50 \%$; PA3, PcomA DRD between 10 and 50\%.

Results: With A1 asymmetry, the ICA diameter of the dominant A1 is significantly greater than the contralateral side. Significant differences of bilateral ICA flow were present in the AA1 and AA2 groups (mean flow difference 42.9 and 30.7\%, respectively). Significant bilateral ICA diameter and flow differences were only found in the PA1 group. Linear regression analysis of ICA diameter and flow found a moderately positive correlation between ICA diameter and flow in all AA groups, with a $1 \mathrm{~mm}$ increment in vessel diameter corresponding to a $62.6 \mathrm{ml}$ increment of flow volume. The product of bilateral ICA diameter and flow volume difference (ICA-PDF) could be a potential discriminator with a cutoff of 4.31 to predict A1 asymmetry $\geq 50 \%$ with a sensitivity of 0.81 and specificity of 0.76 .

Conclusions: The study verifies that A1 asymmetry causes unequal bilateral carotid inflow, and consequently different bilateral ICA diameters. Adjustment of the inflow boundary conditions according to the COW variants would be necessary to improve the accuracy of numerical simulation.

Keywords: Cerebral blood flow, Carotid artery, MR angiography, Cerebral hemodynamics, Neuroanatomy, Ultrasound

\footnotetext{
* Correspondence: porthoswu@yahoo.com.tw

'Department of Biomedical Imaging and Radiological Sciences, National Yang-Ming University, Taipei, Taiwan

2Department of Medical Sciences Industry, Chang Jung Christian University, Tainan, Taiwan

Full list of author information is available at the end of the article
}

(C) The Author(s). 2020 Open Access This article is licensed under a Creative Commons Attribution 4.0 International License, which permits use, sharing, adaptation, distribution and reproduction in any medium or format, as long as you give appropriate credit to the original author(s) and the source, provide a link to the Creative Commons licence, and indicate if changes were made. The images or other third party material in this article are included in the article's Creative Commons licence, unless indicated otherwise in a credit line to the material. If material is not included in the article's Creative Commons licence and your intended use is not permitted by statutory regulation or exceeds the permitted use, you will need to obtain permission directly from the copyright holder. To view a copy of this licence, visit http://creativecommons.org/licenses/by/4.0/ The Creative Commons Public Domain Dedication waiver (http://creativecommons.org/publicdomain/zero/1.0/) applies to the data made available in this article, unless otherwise stated in a credit line to the data. 


\section{Background}

In patients with cerebral aneurysms, numerical simulation could provide important hemodynamic information about the aneurysm formation, enlargement, and rupture [1, 2]. Accurate computation fluid dynamic calculations are based on 2 basic conditions: 1) detailed 3-dimensional (3D) angio-architecture and 2) accurate/reasonable physiologic setting of the target vascular tree [2-4]. However, essential patient-specific physiologic data, such as flow volume and flow rate of the proximal parent artery, are usually lacking for numerical analysis. Consequently, average blood flow data from the general population, rather than patient-specific values, are used [5-8].

It is reported that approximately half of the population has Circle of Willis (COW) variants [9-12]. On the other hand, cerebral aneurysms are not uncommon in patients with asymmetric COW variants, such as anterior communicating artery (AcomA) aneurysms in A1 aplasia, and posterior communicating artery ( $\mathrm{PcomA}$ ) aneurysms in fetal posterior cerebral artery (F-PCA) [13, 14]. Moreover, carotid flow contralateral to A1 aplasia, and ipsilateral to F-PCA, has been shown to be greater than those with a normal COW [15-18]. Total brain blood flow and distribution in different COW-types also had been proposed [16]. It had been shown that inflow boundary condition $[3,19]$, especially parent artery flow volume and the conjoint inflow ratio, affect the hemodynamic parameters of cerebral aneurysms. Therefore, adjustment of inflow boundary conditions for cerebral aneurysm analysis according to different COW types is important for obtaining reliable simulation results.

Thus, the purpose of this study was to investigate the association of bilateral ICA flow in healthy adults with asymmetric COW variants, and develop a method for predicting COW asymmetry and the representative carotid flow volume.

\section{Methods \\ Patients}

This retrospective study was approved by the Institutional Review Board of our hospital. The requirement to obtain informed consent was waived due to its retrospective nature.

We retrospectively reviewed the PACS of our institution for subjects who received simultaneous head and neck MRA and carotid duplex sonography from January 2017 to June 2018 as part of a routine health examination. A total of 223 healthy subjects without any history or symptoms of cerebrovascular disease were identified.

Based on the imaging studies, 3 subjects were excluded due to segmental narrowing ( $>50 \%$ ) of the common/internal carotid arteries, 4 due to proximal anterior cerebral artery (ACA)/ middle cerebral artery stenosis, 1 due to a persistent trigeminal artery, 2 due to vascular anomalies such as cerebral aneurysm, 2 due to arteriovenous malformation/fistula, and 1 due to a moyamoya syndrome. These 13 excluded subjects were used for the interobserver reliability test. Thus, 210 subjects (133 males, 77 females; mean age $54 \pm 9$ years; range, 31 to 76 years) were included in the analysis.

\section{Imaging studies}

Three-dimensional time-of-flight magnetic resonance angiography (TOF-MRA) of the head was obtained with the parameters: TR/TE, $21 / 2 \mathrm{~ms}$; flip angle, $20^{\circ}$; FOV, $200 \mathrm{~mm}$; matrix, $320 \times 192$; NEX, 1 . The major extracranial arteries in the neck were visualized by contrastenhanced MRA on a $3 \mathrm{~T}$ MR scanner (Discovery MR 750, GE Medical Systems, Milwaukee, WI, USA) using a single dose $(0.1 \mathrm{mmol} / \mathrm{kg} ; 5-7 \mathrm{ml})$ of gadobutrol (GdBT-DO3A, Gadovist ${ }^{\mathrm{ma}}$, Bayer Healthcare, Leverkusen, Germany) with an injection rate of $1.5 \mathrm{ml} / \mathrm{s}$ and MR parameters of TR/TE, 4/1 ms; flip angle, $25^{\circ}$; FOV, 300 mm; matrix, $320 \times 224$; and NEX, 1 . Carotid Doppler sonography was performed by the same technician with more than 10 years of experience using a Philips HD15 ultrasound system to evaluate bilateral ICA flow volume. For ICA flow volume measurement, a straight ICA segment at least $2 \mathrm{~cm}$ above the carotid bulb was selected with the doppler angle of incidence adjusted at or below 60 degrees. At the same site, the sample volume box was put to cover the entire vessel diameter (d). The anglecorrected time-average flow velocity (TAV) was determined over 3 to 5 complete cardiac cycles. The ICA flow volume was calculated as the product of TAV and the cross-sectional area (A) of the vessel according to the formula $\mathrm{FV}=\mathrm{TAV} \times \mathrm{A}=\mathrm{TAV} \times\left[(\mathrm{d} / 2)^{2} \mathrm{x} \pi\right]$.

\section{MR imaging interpretations}

At first, vessel diameter and COW calcification of the 13 excluded subjects were recorded by two experienced neuroradiologists (TCW and TYC with 12 and 17 years of experience, respectively) for the interobserver reliability tests. Due to substantial to almost perfect reproducibility (ICC values of $0.82-0.97$ ), the vessel diameter measurements of all 210 included subjects were completed by only one reader (TCW). For COW classification, the diameter ratios between the bilateral A1 segments and between the ipsilateral PcomA and P2 segments were recorded (Fig. 1a, b). The diameters of the bilateral distal cervical ICAs were measured at $1 \mathrm{~cm}$ below the petrous segment of the ICA (Fig. 1c). In each case, the diameter of the dominant A1 segment was set as $100 \%$, and the diameter of the non-dominant A1 segment was set as the percentage compared to the dominant A1 segment. Bilateral PcomA diameters were transformed into the percentage of the ipsilateral P2 


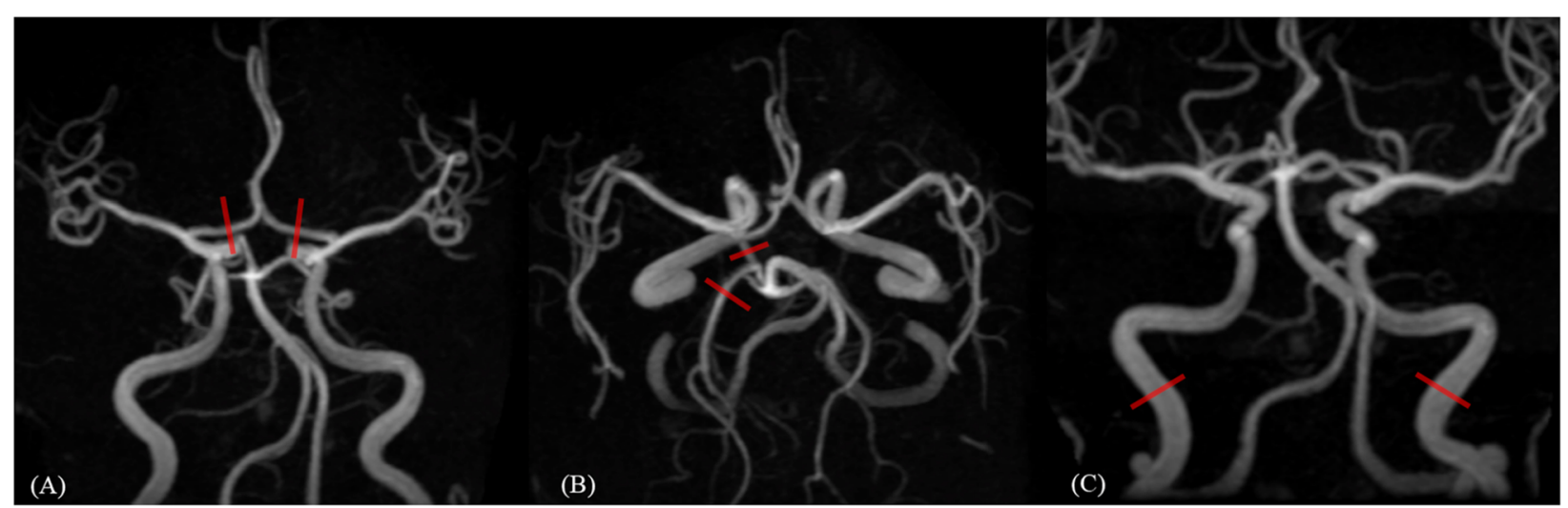

Fig. 1 Examples of vascular diameter measurement. a) Typical location of bilateral A1 diameter measurement at in the middle of the A1 segment. b) Typical location of PcomA and P2 diameter measurement at in the middle of the PcomA and proximal P2 segment, respectively. Note there was no PcomA on the contralateral side. c) Typical location of bilateral distal cervical ICA diameter measurement at $1 \mathrm{~cm}$ below the petrous ICA segment

segment diameters. F-PCA was defined as a PcomA diameter equal to the ipsilateral P2 segment diameter with an absence of the ipsilateral P1 segment.

The classification of COW variants is summarized in Fig. 2. Three ACA asymmetry (AA) groups were defined based on the diameter ratio difference of bilateral A1 segments: AA1 group, 1 side A1 aplasia; AA2, bilateral A1 diameter ratio difference $\geq 50 \%$; AA3, bilateral A1 ratio difference between 10 and 50\%. Similarly, 3 PcomA asymmetry (PA) groups were defined: PA1 group, $1 \mathrm{~F}$ PCA, and absent PcomA on the contralateral side; PA2, bilateral PcomA diameter ratio difference $\geq 50 \%$; PA3, bilateral PcomA diameter ratio difference between 10 and 50\%. According to the vessel diameter, bilateral A1 segments and PcomAs in each patient were denoted as a dominant or non-dominant side. Symmetry was defined as both bilateral A1 segment and PcomA diameter ratio differences $<10 \%$, with the exclusion of cases with bilateral F-PCAs.

Several parameters were used to determine the ability of ICA diameter and flow volume for prediction of COW variants: (1) Bilateral ICA diameter difference; (2) Bilateral ICA flow volume difference; (3) Bilateral ICA flow volume difference percentage $(2 \times$ bilateral ICA flow difference/ bilateral ICA sum); (4) Product of bilateral ICA diameter and flow volume difference (ICA-PDF), expressed as ICA diameter difference (right ICA diameter - left ICA diameter) $\times$ ICA flow volume difference percentage $[2 \times$ (right ICA flow - left ICA flow) $/$ (right ICA flow + left ICA flow)].

\section{Statistical analysis}

Vessel diameter and flow volume measurements were expressed as mean and standard deviation. Vessel

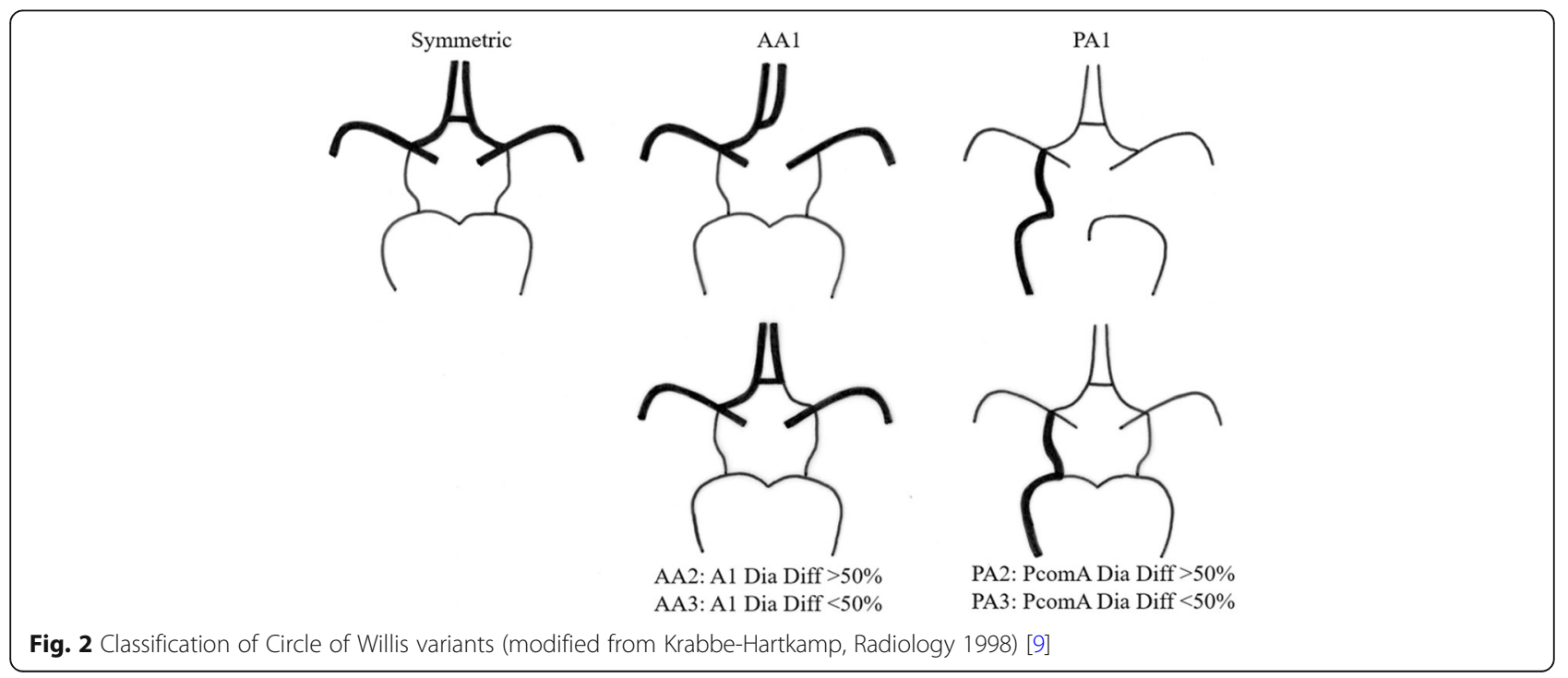


diameter and flow volume were compared in the following ways with different statistical tests: 1) One-way ANOVA and Bonferroni method for multi-intergroup analysis; 2) Student t-test for comparisons between each AA/PA subgroup and symmetric group; 3) Paired t-test for intragroup analysis of each subgroup to compare dominant vs. non-dominant side and right vs. left side. Linear regression analysis was used to examine the relations between ICA diameter and flow volume in each COW type. To examine the ability of ICA diameter and flow parameters for prediction of each COW variant, receiver operating characteristic (ROC) curve analysis was performed. Inter-observer reliability for COW calcification of 13 excluded cases was determined by using the Cohen $\mathrm{k}$ coefficient. For continuous data, the intraclass correlation coefficient (ICC) was calculated with the two-way random model and absolute agreement on average measures. The Cohen $\mathrm{k}$ and ICC were interpreted according to methods described by Landis et al. [20]. Cohen K coefficient values of $0.85 \sim 0.96$ were obtained for categorical COW classification and ICC values of $0.82-0.97$ were obtained for the continuous data, both indicating almost perfect reproducibility. All data analyses were performed using the statistical software package SPSS for Windows version 24.0 (IBM, Chicago, IL, USA). Values of $P$-value $<0.05$ were considered to indicate statistical significance.

\section{Results}

\section{Vascular anatomy}

The demographic data of the subjects are summarized in Table 1. All 210 subjects were asymptomatic HanChinese adults, and only 81 (38.6\%) had complete symmetric of the COW. Seven subjects with bilateral FPCAs and symmetric A1s were not included in the symmetric group due to a lack of bilateral P1 segments.
Sixty-seven subjects had asymmetric A1 segments (31.9\% of all cases), including 19 (9\%; AA1 group) with unilateral A1 aplasia, 33 (15.7\%; AA2 group) with $\geq 50 \%$ A1 asymmetry, and 15 (7.1\%; AA3 group) with $<50 \%$ A1 asymmetry.

Seventy-eight subjects (37.1\% of all cases) were included in the PA group, including 15 in the PA1 group (7.1\%) with a unilateral F-PCA and absent contralateral PcomAA, 45 in the PA2 group (21.4\%) with $\geq 50 \%$ PcomA asymmetry, and 18 in the PA3 group (8.6\%) with $<50 \%$ PcomA asymmetry. Twenty-three subjects had both $\mathrm{A} 1$ and PcomA asymmetry. In these subjects, the dominant A1 was most likely to be on the same side as the non-dominant PcomA $(19$ patients, $P<0.001$, McNemar's test). Only 4 subjects had the dominant A1 and dominant PcomA on the same side.

\section{Comparison of vessel diameters and flow in different subgroups \\ AA group}

When ACA asymmetry was present, there were significant differences in ICA diameter between dominant and non-dominant sides in the AA1, AA2, and AA3 groups (Fig. 3a). Compared with the symmetric group, the AA1 and AA2 groups had a significantly larger ICA diameter on the dominant side and a significantly smaller ICA diameter on the non-dominant side. Similarly, significant differences in bilateral ICA flow were also found in the AA1 and AA2 groups (Fig. $3 \mathrm{~b}$ ). The average bilateral ICA flow volume difference percentages of the AA1, AA2, and AA3 groups were 42.9, 30.7, and 29\%, respectively (Table 2). A greater asymmetry between the bilateral A1 segments tended to be associated with a larger difference between the bilateral ICA flow volume.

Table 1 Subjects demographic data by Circle of Willis variants

\begin{tabular}{|c|c|c|c|c|c|c|c|c|c|c|}
\hline & \multirow[t]{2}{*}{ All } & \multirow[t]{2}{*}{ Symmetric $^{a}$} & \multicolumn{3}{|c|}{ A1 Asymmetry (AA group) ${ }^{b}$} & \multirow[b]{2}{*}{$P$-value } & \multicolumn{3}{|c|}{ 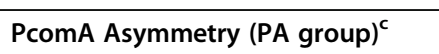 } & \multirow[b]{2}{*}{$P$-value } \\
\hline & & & $\overline{A A 1}$ & AA2 & AA3 & & $P A 1^{d}$ & PA2 & PA3 & \\
\hline Number of cases & 210 & $81(38.6 \%)$ & $19(9 \%)$ & $33(15.7 \%)$ & $15(7.1 \%)$ & & $15(7.1 \%)$ & $45(21.4 \%)$ & $18(8.6 \%)$ & \\
\hline Age (years) & $53.9 \pm 9.4$ & $50.4 \pm 9.3$ & $52.6 \pm 11.5$ & $54.6 \pm 10.1$ & $49.9 \pm 8.3$ & 0.344 & $55.4 \pm 7.9$ & $53.3 \pm 9.5$ & $51.8 \pm 7.0$ & 0.507 \\
\hline Right-side & & & $6(31.6 \%)$ & $8(24.2 \%)$ & $7(46.7 \%)$ & 0.311 & $10(66.7 \%)$ & $29(64.4 \%)$ & $14(77.8 \%)$ & 0.588 \\
\hline \multicolumn{11}{|l|}{ Sex } \\
\hline Female & 77 (36.7\%) & $32(39.5 \%)$ & $7(36.8 \%)$ & $8(24.2 \%)$ & $4(26.7 \%)$ & 0.601 & $7(46.7 \%)$ & $15(33.3 \%)$ & $10(55.6 \%)$ & 0.262 \\
\hline Male & $133(63.3 \%)$ & $49(60.5 \%)$ & $12(63.2 \%)$ & $25(75.8 \%)$ & $11(73.3 \%)$ & & $8(53.3 \%)$ & $30(66.7 \%)$ & $8(44.4 \%)$ & \\
\hline Height (cm) & $165.2 \pm 8.1$ & $165.2 \pm 8.7$ & $166.7 \pm 8.2$ & $165.5 \pm 6.6$ & $166.1 \pm 6.1$ & 0.841 & $163.3 \pm 7.8$ & $165.6 \pm 8.7$ & $163.4 \pm 7.6$ & 0.494 \\
\hline Weight (Kg) & $68.0 \pm 13.2$ & $69.6 \pm 14.6$ & $69.4 \pm 13.7$ & $65.8 \pm 9.9$ & $69.7 \pm 13.7$ & 0.428 & $64.9 \pm 11.4$ & $67.9 \pm 13.5$ & $64.5 \pm 11.0$ & 0.543 \\
\hline Heart rate (/min) & $67.3 \pm 10.0$ & $66.8 \pm 11.1$ & $65.8 \pm 10.4$ & $68.3 \pm 8.0$ & $65.5 \pm 12.6$ & 0.551 & $67.8 \pm 8.2$ & $68.4 \pm 7.9$ & $69.7 \pm 12 / 0$ & 0.820 \\
\hline
\end{tabular}

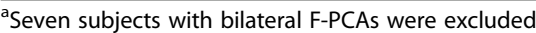

${ }^{\mathrm{b}}$ Twenty-three patients in the AA group had PcomA asymmetry, including 2 PA1, 14 PA2, and 7 PA3

'Twenty-three patients in the PA group had $A 1$ asymmetry, including $5 A A 1,13 A A 2$, and $5 A A 3$

${ }^{\mathrm{d}}$ Thirty-seven subjects with 45 F-PCA, with 20 right-side F-PCA, 9 left-side F-PCA, and 8 bilateral F-PCAs 


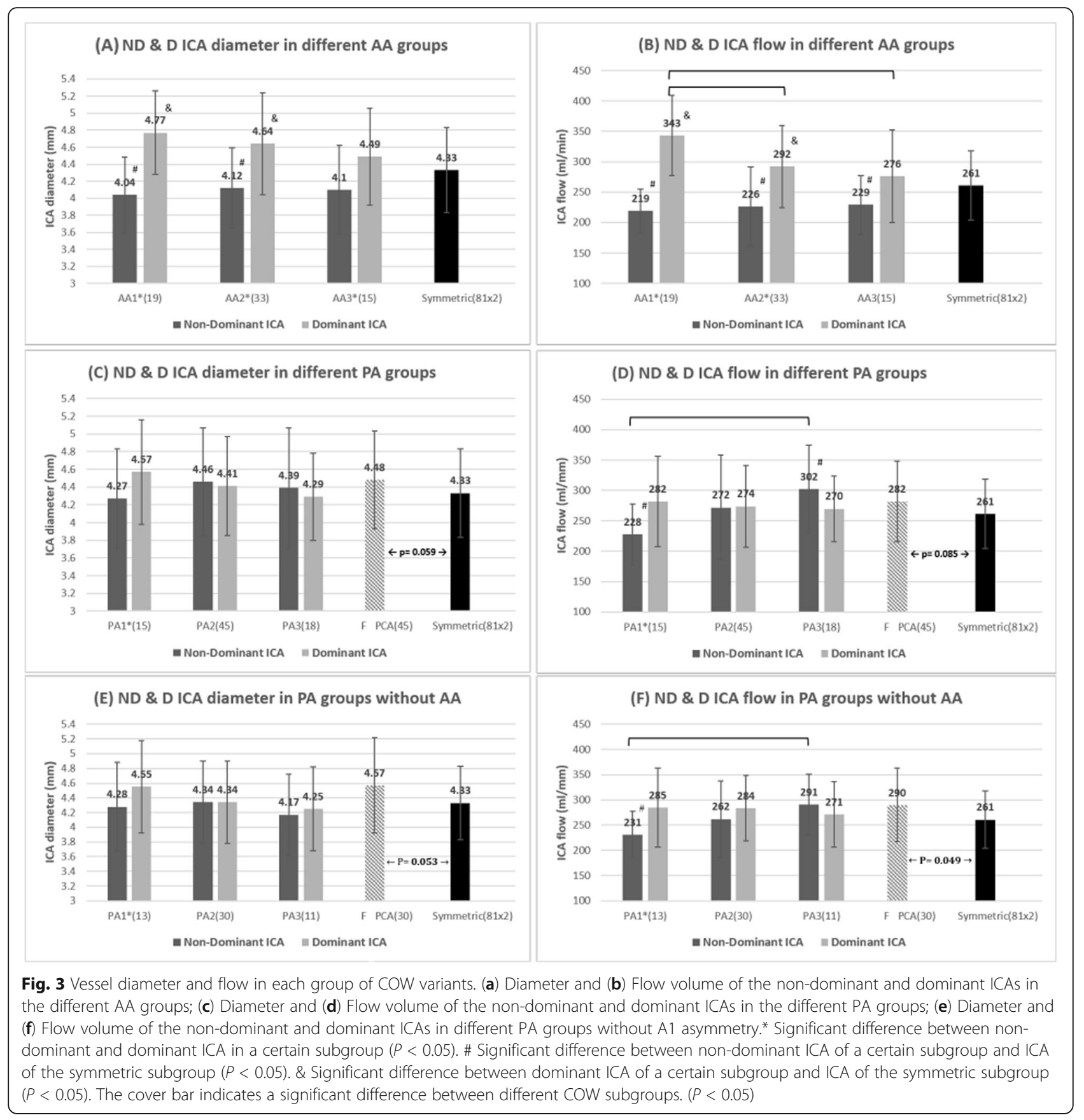

\section{PA group \& F-PCA}

A significant difference in bilateral ICA diameter and flow was only found in the PA1 group with unilateral F-PCA and no contralateral PcomA. If an F-PCA was present, there was a trend for the ipsilateral ICA to have a larger diameter and higher flow volume as compared with the symmetric group (Fig. 3c, d). However, there was no significant difference between these 2 groups concerning diameter $(P=0.059)$ and flow volume $(P=0.085)$. On the other hand, the difference between ICA flow ipsilateral to the FPCA and in the symmetric group reached statistical significance $(P=0.049)$ after the exclusion of 15 patients with an F-PCA with concomitant A1 asymmetry (Fig. 3e, f).

\section{Association of ICA diameter with ICA flow}

A moderately positive linear correlation between ICA diameter and ICA flow in the AA group $\left(R^{2}=0.238\right)$ was noted (Fig. 4a) According to the linear equation, there was a $62.6 \mathrm{ml}$ increase in the ICA flow volume per $1 \mathrm{~mm}$ increase in the ICA diameter. Based on the average ICA flow volume of $265.9 \mathrm{ml} / \mathrm{min}$ in the AA group, it implied a change of $23.5 \%$ of the ICA flow volume per $1 \mathrm{~mm}$ 
Table 2 ICA flow and diameter parameters for each group of COW variants

\begin{tabular}{|c|c|c|c|c|c|c|c|c|c|c|c|c|}
\hline & \multirow[t]{2}{*}{ All } & \multirow[t]{2}{*}{ Symmetric } & \multicolumn{5}{|c|}{ A1 Asymmetry (AA group) } & \multicolumn{4}{|c|}{ PcomA Asymmetry (PA group) } & \multirow[b]{2}{*}{$P$ value } \\
\hline & & & AA1 & AA2 & AA3 & Non-AA & $P$ value & PA1 & PA2 & PA3 & Non-PA & \\
\hline Number of subjects & 210 & 81 (38.6\%) & $19(9 \%)$ & $33(15.7 \%)$ & $15(7.1 \%)$ & $143(68.1 \%)$ & & $15(7.1 \%)$ & $45(21.4 \%)$ & $18(8.6 \%)$ & $132(62.9 \%)$ & \\
\hline ICA-PDF & $6.9 \pm 16.6$ & $-0.1 \pm 7.9$ & $30.8 \pm 22.4$ & $17.4 \pm 20.3$ & $9.5 \pm 16.4$ & $1.0 \pm 9.1$ & $<0.0001$ & $7.3 \pm 14.8$ & $6.2 \pm 13.3$ & $7.3 \pm 22.5$ & $7.0 \pm 17.0$ & 0.993 \\
\hline $\begin{array}{l}\text { ICA diameter } \\
\text { difference }(\mathrm{mm})\end{array}$ & $0.37 \pm 0.32$ & $0.22 \pm 0.22$ & $0.76 \pm 0.33$ & $0.55 \pm 0.38$ & $0.48 \pm 0.38$ & $0.26 \pm 0.22$ & $<0.0001$ & $0.40 \pm 0.29$ & $0.41 \pm 0.34$ & $0.40 \pm 0.37$ & $0.34 \pm 0.31$ & 0.655 \\
\hline $\begin{array}{l}\text { ICA flow difference } \\
(\mathrm{ml} / \mathrm{min})\end{array}$ & $65.9 \pm 51.6$ & $51.0 \pm 38.8$ & $124.6 \pm 73.2$ & $76.9 \pm 45.8$ & $76.2 \pm 62.2$ & $54.6 \pm 42.0$ & $<0.0001$ & $65.1 \pm 47.3$ & $64.0 \pm 54.2$ & $72.9 \pm 53.4$ & $65.6 \pm 51.5$ & 0.943 \\
\hline $\begin{array}{l}\text { ICA flow difference } \\
\text { percentage (\%) }\end{array}$ & $24.5 \pm 17.8$ & $19.6 \pm 14.3$ & $42.9 \pm 24.1$ & $30.7 \pm 18.6$ & $29.0 \pm 19.0$ & $20.2 \pm 14.2$ & $<0.0001$ & $25.0 \pm 14.9$ & $22.5 \pm 16.0$ & $25.5 \pm 18.0$ & $25.1 \pm 18.7$ & 0.852 \\
\hline
\end{tabular}

change in the ICA diameter. On the other hand, no significant association was noted between ICA diameter and flow volume in either the PA (Fig. 4b) and symmetric groups (Fig. 4c). Carotid diameter and flow differences for each group of COW variants are shown in Table 2. All parameters, including ICA diameter difference, ICA flow difference, ICA flow difference percentage, and product of bilateral ICA diameter and flow difference (ICA-PDF) of each AA group exhibited significant differences. Among them, ICA-PDF had the highest area under the ROC curve $(\mathrm{AUC}=0.807)$ for discriminating the AA1 and AA2 groups from the others, followed by ICA diameter difference $(\mathrm{AUC}=0.771)$, ICA flow difference percentage (AUC $=0.703$ ), and ICA flow difference (AUC $=0.695$ ) (Fig. 5a). For the prediction of A1 absence, ICA-PDF and ICA-diameter difference exhibited even higher accuracy for discriminating the AA1 group from the other groups (Fig. 5b). The optimal cutoff value for bilateral A1 asymmetry $\geq 50 \%$ was a $\mathrm{PDF}=$ 4.31 with a sensitivity of 0.81 and specificity of 0.76 .

\section{Discussion}

This study attempted to clarify the effect of asymmetric COW variants on carotid flow changes and proposed an easy estimate of the representative carotid flow volume.
In the present study, 52 of the 210 cases (34.7\%) had bilateral A1 asymmetry $\geq 50 \%$, in whom there was significantly greater dominant ICA flow with larger dominant ICA diameter, and lower non-dominant ICA flow with smaller non-dominant ICA diameter, as compared with the symmetric group. There was a moderately positive association between ICA vessel diameter and ICA flow volume in the AA groups, with a $1 \mathrm{~mm}$ increment in vessel diameter corresponding to a $62.6 \mathrm{ml}$ increment of flow volume. Moreover, an ICA-PDF cutoff value of 4.31 was found to be a useful predictor of bilateral A1 asymmetry $\geq 50 \%$.

While the COW serves as an important intracranial collateral pathway, there are multiple incomplete or asymmetric variants with variable prevalence according to different classification criteria, including A1 absence (2.6-15.4\%; 9\% in our study), A1 hypoplasia (2.6-28.9\%; $15.7 \%$ in our study), true F-PCA without a P1 segment (0.9-29.5\%; 10.7\% in our study), and F-PCA with P1 hypoplasia $(4.5-37.2 \%$; $4.5 \%$ in our study) [9-12, 14, 15 , 17, 18, 21-23]. In our study, we used a bilateral A1 and PcomA diameter ratio difference of $50 \%$ to define asymmetry rather than the usual criteria using an absolute vessel diameter of $1.0 \mathrm{~mm}$ as a cutoff value. Based on reports indicating the mean diameters of the A1 segment
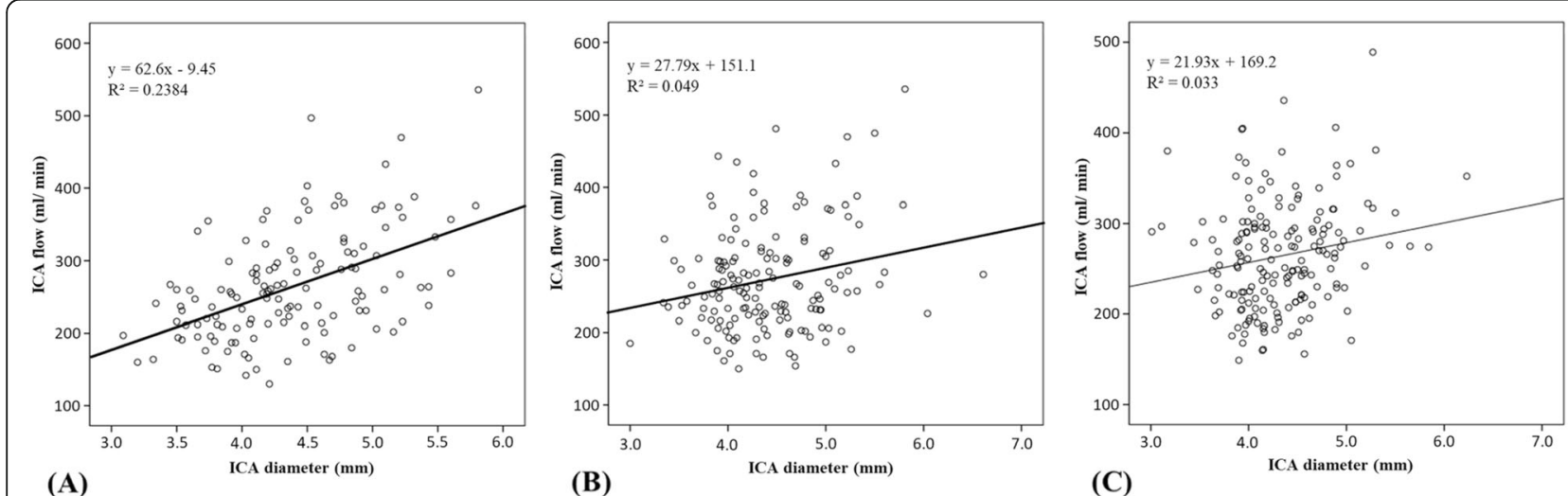

Fig. 4 Linear regression analysis of ICA diameter and ICA flow in each group of COW variants. (a) AA group, (b) PA group, and (c) symmetric group 


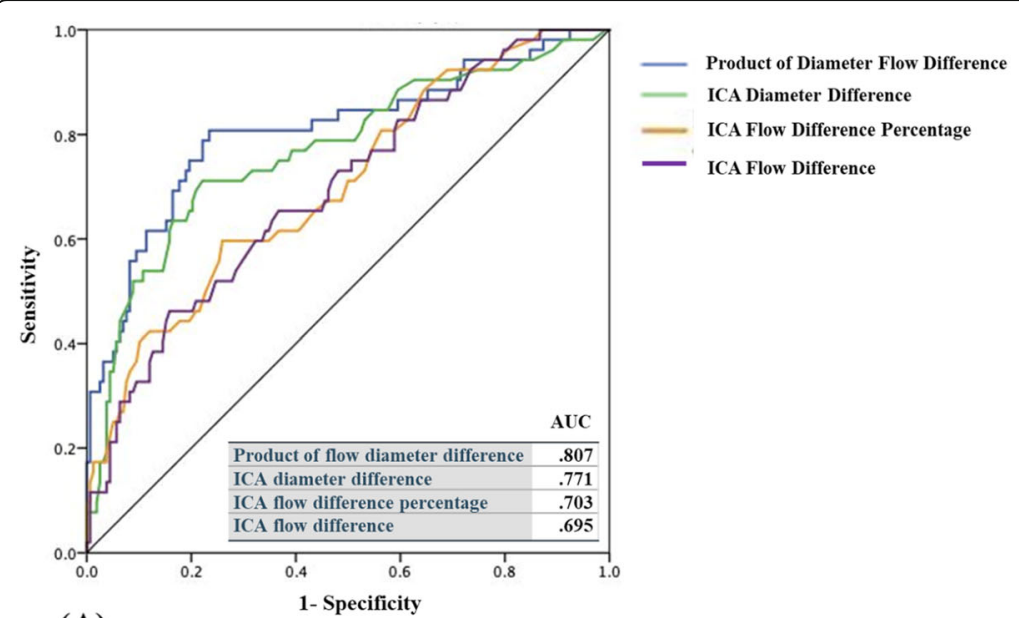

(A)

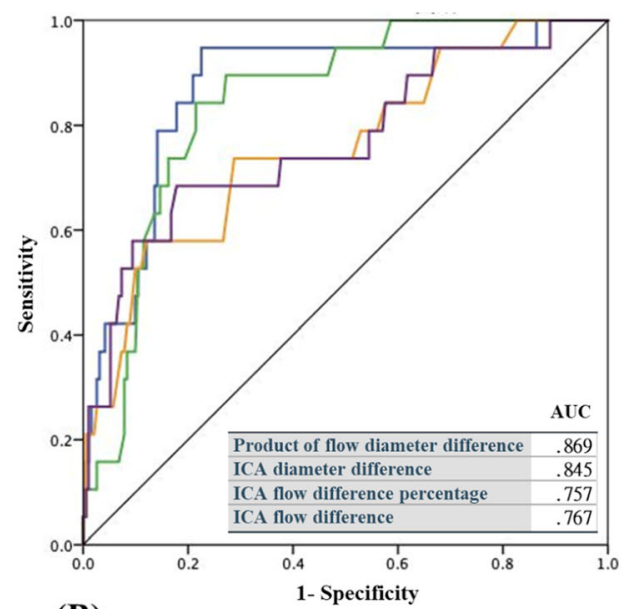

(B)

Fig. 5 ROC curve of all parameters of ICA diameter and flow difference of different AA groups. (a) AA1 \& AA2 vs others and (b) AA1 vs others

and the P2 segment are $2 \mathrm{~mm}[9,11]$, a bilateral vessel diameter ratio difference of $50 \%$ equals a $1 \mathrm{~mm}$ cutoff value for the hypoplastic vessels. This vessel diameter ratio had been used in several studies focused on the effect of inflow inequality on cerebral aneurysms [23-26].

Our study showed a mean individual carotid flow difference percentage of $42.9 \%$ in the AA1 group. The result was consistent with several previous studies showing that the carotid flow ipsilateral to A1 aplasia is significantly lower than that of the contralateral side, with the flow difference percentage ranging from 34 to 50\% [1518]. Moreover, we also demonstrated that there was a significantly higher individual carotid flow difference percentage (30\%) when A1 asymmetry was present. Since each A1 segment carries about $10 \%$ of the total brain flow to the ipsilateral hemisphere [17, 24], A1 segment asymmetry indicates redistribution of bilateral A1 flow and is crucial for computational hemodynamic studies for 2 reasons. First, A1 hypoplasia is associated with AcomA aneurysms [1, 13, 23, 27]. This relation can be explained by hemodynamic studies using either an experimental design with an A1 diameter ratio of $\geq 50 \%$ [25], or patient-specific 3D geometry with an unequal A1 inflow [28]. Both types of studies [25, 28] showed elevated intra-aneurysmal wall shear stress in the setting of A1 hypoplasia or unequal flow that would trigger AcomA aneurysm formation. Our results further emphasized that A1 asymmetry, even with a diameter difference of $<50 \%$, could also cause unequal inflow and might be associated with Acom aneurysm formation. Second, several studies have indicated the importance of using patient-specific inflow boundary conditions to obtain reliable computational fluid dynamic results, especially for aneurysms with more than 2 inflow avenues, such as AcomA aneurysms [3, 19, 25, 28, 29]. Venugopal et al. [19] showed that the wall shear stress distribution on an aneurysm surface is sensitive to the bilateral A1 flow ratio and flow rate by using different inflow boundary conditions for a patient-specific AcomA aneurysm geometry with an original flow ratio of 1.87. Similarly, Karmonik et al. [29] reported that changes in the flow distribution of bilateral A1 segments could cause variations of the average wall shear stress as high as 43\%, again using a patient-specific AcomA aneurysm model with an original flow ratio of 1.72 . On the other hand, blood flow changes of the parent artery would not change the characterization of the intra-aneurysmal flow pattern substantially in the setting of a side-wall aneurysm/terminal aneurysm or AcomA aneurysm with relatively symmetric A1 segments [30]. In our study, we proposed a linear equation between the ipsilateral ICA diameter and ICA flow volume to provide a representative inflow boundary condition for the numerical simulation while A1 asymmetry is present.

As for PcomA asymmetry, only the PA1 group exhibited a significant carotid flow and diameter difference, but to a lesser extent of $25 \%$. A significantly higher carotid flow with an F-PCA compared with the symmetric group was only found after the exclusion of coincident A1 asymmetry. When A1 asymmetry occurred simultaneously with PcomA asymmetry (23 cases), a nondominant A1 (19 cases) was more frequently on the same side of the dominant PcomA. A PcomA usually serves as a conduit connecting the anterior and posterior circulation to provide a collateral pathway when there is proximal vessel comprise or there is an incomplete COW. The average net flow of a PcomA is usually low, and in an anterior to posterior direction, and accounts for about $5 \%$ of the ipsilateral carotid flow [31]. Considering all the aforementioned findings, it is reasonable 
that PcomA asymmetry has little influence on carotid flow changes.

In all AA groups and the PA1 group, there was a consistent relation between dominant and non-dominant carotid diameter and flow, i.e., there was larger vessel diameter and higher carotid flow on the dominant side. This finding is consistent with a "form-function" relation, wherein the form (anatomy: vessel radius) proportionately informs its function (physiology: blood flow). This concept has been extensively applied in the study of coronary artery disease [32, 33]. Similar findings have also been reported in studies of carotid flow, such as a small carotid diameter ipsilateral to A1 absence [21], and a linear relationship between whole brain volume and cerebral blood flow [16]. Cebral et al. [34] studied the flow-area relation in the carotid arteries of 11 healthy adults using the least-squares method for curve fitting and reported an average relative error between the predicted and the measured ratio to be $20 \%$. This relation is also reflected in our finding of a moderately positive linear correlation (Fig. 4a) between carotid diameter and carotid flow in the AA groups $\left(r^{2}=0.238\right)$. Despite a significant difference in carotid diameter and flow between each of the AA groups, there was also a large standard deviation in each parameter owing to large individual variances. To cancel out the individual variances (Table S1 in the supplement) and amplify the flow-diameter difference in the subjects with A1 asymmetry (Figure S1 in the supplement), we proposed the product of bilateral ICA diameter and flow difference (ICA-PDF) as a potential discriminator. Recognition of an incomplete COW could offer stroke risk stratification in patients vulnerable to proximal artery compromise, such as those receiving cardiovascular surgery or carotid artery trapping [35].

Several limitations of our study should be addressed. First, the majority of subjects were middle-aged (40-60 years old, 64\%) healthy Han-Chinese adults. The progressive decline of cerebral blood flow at a rate of $3 \mathrm{ml}$ per year has been also reported [36]. The estimate of carotid flow in younger or aged populations might need adjustment. Second, it's hard to assure the bright vessel lumen on TOF-MRA reflecting the "true" vessel size, especially when scanning a hypoplastic vessel. Moreover, the vessel diameter was calculated by only 1 reader. Thus, to minimize the measurement error of small-sized A1 segments and PcomA $(<3 \mathrm{~mm})$, the vessel diameter ratio compared to the contralateral A1 or ipsilateral P2 segment, rather than the exact vessel diameter, was used for COW classification. It was reflected by the almost perfect reproducibility of categorical COW calcification in the 13 excluded subjects (Cohen $\mathrm{K}$ coefficient values of $0.85 \sim 0.96$ ). Third, there was no validation performed for the estimate of carotid flow by the ipsilateral carotid diameter in A1 asymmetry and patients with specific neurovascular diseases such as cerebral aneurysms. Validation with another dataset, or with prospective study might be helpful.

\section{Conclusion}

A1 asymmetry plays an important role in ICA flow distribution, contributing to bilateral unequal carotid inflow and significant carotid diameter difference. When A1 asymmetry is present, there is a moderately positive linear correlation between carotid diameter and carotid flow, with a $1 \mathrm{~mm}$ increment in vessel diameter corresponding to a $62.6 \mathrm{ml}$ increment of flow volume. Our study improved the understanding of the association of bilateral ICA flow in healthy adults with asymmetric COW variants. Our results can potentially be applied to improve the accuracy of numerical simulation by the adjustment of the inflow boundary conditions according to the COW variants.

\section{Supplementary information}

Supplementary information accompanies this paper at https://doi.org/10 1186/s12883-020-01831-z

Additional file 1: Figure S1.ICA diameter difference and ICA flow difference percentage for each AA subgroup and non-AA subgroup.

Additional file 2: Table S1. ICA flow \& diameter parameters for each AA subgroup and non-AA subgroup.

\section{Abbreviations}

COW: Circle of Willis; ICA: Internal carotid artery; ACA: Anterior cerebral artery; AcomA: Anterior communicating artery; A1: The 1st segment of anterior cerebral artery; AA: A1 asymmetry; PcomA: Posterior communicating artery; P1: The 1st segment of posterior cerebral artery; PA: P1 asymmetry; FPCA: Fetal posterior cerebral artery; TOF: Time-of-flight; MRA: Magnetic resonance angiography; TAV: Time-average flow velocity; DRD: Diameter ratio difference; ICA-PDF: Product of bilateral ICA diameter and flow volume difference

\section{Acknowledgements}

Not applicable.

\section{Authors' contributions}

TW participated in the study design, image data acquisition and interpretation, and drafted the manuscript. TC participated in the image data acquisition and interpretation, and manuscript writing. CK participated in the image data acquisition, statistical analysis and manuscript writing. JC and CL participated in the study conception and critical revision of the manuscript for important intellectual content. All authors read and approved the final manuscript.

\section{Funding}

No funding was received.

\section{Availability of data and materials}

The datasets used and analysed during the current study are available from the corresponding author on reasonable request.

\section{Ethics approval and consent to participate}

This retrospective study was approved by the institutional review board of the Chi-Mei Medical Center (IRB Serial No.:10707-007), and the need for informed consent was waived. 


\section{Consent for publication}

Not applicable.

\section{Competing interests}

The authors declare that they have no conflict of interest.

\section{Author details}

'Department of Biomedical Imaging and Radiological Sciences, National Yang-Ming University, Taipei, Taiwan. ${ }^{2}$ Department of Medical Sciences Industry, Chang Jung Christian University, Tainan, Taiwan. ${ }^{3}$ Department of Medical Imaging, Chi-Mei Medical Center, Tainan City, Taiwan. ${ }^{4}$ Graduate Institute of Medical Sciences, Chang Jung Christian University, Tainan, Taiwan. ${ }^{5}$ Center of General Education, Chia Nan University of Pharmacy and Science, Tainan, Taiwan. ${ }^{6}$ Department of Radiology, E-DA Hospital, E-DA Cancer Hospital, I-Shou University, Kaohsiung, Taiwan. ${ }^{7}$ Center for Functional Onco-Imaging of Radiological Sciences, School of Medicine, University of California, Irvine, California, USA. ${ }^{8}$ Institute of Neuroscience, School of Life Science, National Yang-Ming University, Taipei, Taiwan.

Received: 28 November 2019 Accepted: 15 June 2020

Published online: 20 June 2020

\section{References}

1. Cebral JR, Raschi M. Suggested connections between risk factors of intracranial aneurysms: a review. Ann Biomed Eng. 2013;41(7):1366-83.

2. Cebral JR, Castro MA, Burgess JE, Pergolizzi RS, Sheridan MJ, Putman CM. Characterization of cerebral aneurysms for assessing risk of rupture by using patient-specific computational hemodynamics models. AJNR Am J Neuroradiol. 2005;26(10):2550-9.

3. Castro MA, Putman CM, Cebral JR. Patient-specific computational fluid dynamics modeling of anterior communicating artery aneurysms: a study of the sensitivity of intra-aneurysmal flow patterns to flow conditions in the carotid arteries. AJNR Am J Neuroradiol. 2006;27(10):2061-8.

4. Castro MA, Putman CM, Cebral JR. Computational fluid dynamics modeling of intracranial aneurysms: effects of parent artery segmentation on intraaneurysmal hemodynamics. AJNR Am J Neuroradiol. 2006;27(8):1703-9.

5. Li C, Wang S, Chen J, Yu H, Zhang Y, Jiang F, et al. Influence of hemodynamics on recanalization of totally occluded intracranial aneurysms: a patient-specific computational fluid dynamic simulation study. J Neurosurg. 2012;117(2):276-83.

6. Sforza DM, Kono K, Tateshima S, Vinuela F, Putman C, Cebral JR. Hemodynamics in growing and stable cerebral aneurysms. J Neurointerv Surg. 2016;8(4):407-12.

7. Brinjikji W, Chung BJ, Jimenez C, Putman C, Kallmes DF, Cebral JR. Hemodynamic differences between unstable and stable unruptured aneurysms independent of size and location: a pilot study. J Neurointerv Surg. 2017:9(4):376-80

8. Suzuki T, Takao H, Suzuki T, Kambayashi Y, Watanabe M, Sakamoto H, et al Determining the presence of thin-walled regions at high-pressure areas in Unruptured cerebral aneurysms by using computational fluid dynamics. Neurosurgery. 2016;79(4):589-95.

9. Krabbe-Hartkamp MJ, van der Grond J, de Leeuw FE, de Groot JC, Algra A, Hillen B, et al. Circle of Willis: morphologic variation on three-dimensional time-of-flight MR angiograms. Radiology. 1998;207(1):103-11.

10. Ravikanth R, Philip B. Magnetic resonance angiography determined variations in the circle of Willis: analysis of a large series from a single center. Ci Ji Yi Xue Za Zhi. 2019;31(1):52-9.

11. Maaly MA, Ismail AA. Three dimensional magnetic resonance angiography of the circle of Willis: anatomical variations in general Egyptian population. Egypt J Radiol Nucl Med. 2011;42(3-4):405-12.

12. Hoksbergen AW, Fulesdi B, Legemate DA, Csiba L. Collateral configuration of the circle of Willis: transcranial color-coded duplex ultrasonography and comparison with postmortem anatomy. Stroke. 2000;31(6):1346-51.

13. Songsaeng D, Geibprasert S, Willinsky R, Tymianski M, TerBrugge KG, Krings $T$. Impact of anatomical variations of the circle of Willis on the incidence of aneurysms and their recurrence rate following endovascular treatment. Clin Radiol. 2010;65(11):895-901.

14. Horikoshi T, Akiyama I, Yamagata Z, Sugita M, Nukui H. Magnetic resonance angiographic evidence of sex-linked variations in the circle of Willis and the occurrence of cerebral aneurysms. J Neurosurg. 2002;96(4):697-703.
15. Hendrikse J, van Raamt AF, van der Graaf Y, Mali WP, van der Grond J. Distribution of cerebral blood flow in the circle of Willis. Radiology. 2005;235(1):184-9.

16. Zarrinkoob L, Ambarki K, Wahlin A, Birgander R, Eklund A, Malm J. Blood flow distribution in cerebral arteries. J Cereb Blood Flow Metab. 2015;35(4):648-54.

17. Tanaka H, Fujita N, Enoki T, Matsumoto K, Watanabe $Y$, Murase K, et al. Relationship between variations in the circle of Willis and flow rates in internal carotid and basilar arteries determined by means of magnetic resonance imaging with semiautomated lumen segmentation: reference data from 125 healthy volunteers. AJNR Am J Neuroradiol. 2006;27(8):1770-5.

18. Amin-Hanjani S, Du X, Pandey DK, Thulborn KR, Charbel FT. Effect of age and vascular anatomy on blood flow in major cerebral vessels. J Cereb Blood Flow Metab. 2015;35(2):312-8.

19. Venugopal $P$, Valentino D, Schmitt H, Villablanca JP, Vinuela F, Duckwiler G. Sensitivity of patient-specific numerical simulation of cerebal aneurysm hemodynamics to inflow boundary conditions. J Neurosurg. 2007;106(6):1051-60.

20. Landis JR, Koch GG. The measurement of observer agreement for categorical data. Biometrics. 1977;33(1):159-74.

21. Kane AG, Dillon WP, Barkovich AJ, Norman D, Dowd CF, Kane TT. Reduced caliber of the internal carotid artery: a normal finding with ipsilateral absence or hypoplasia of the A1 segment. AJNR Am J Neuroradiol. 1996; 17(7):1295-301.

22. Chuang YM, Liu CY, Pan PJ, Lin CP. Posterior communicating artery hypoplasia as a risk factor for acute ischemic stroke in the absence of carotid artery occlusion. J Clin Neurosci. 2008;15(12):1376-81.

23. Kwak R, Niizuma H, Suzuki J. Hemodynamics in the anterior part of the circle of Willis in patients with intracranial aneurysms: a study of cerebral angiography. Tohoku J Exp Med. 1980;132(1):69-73.

24. Cornelissen BMW, Schneiders JJ, Sprengers ME, van den Berg R, van Ooij P, Nederveen AJ, et al. Aneurysmal parent artery-specific inflow conditions for complete and incomplete circle of Willis configurations. AJNR Am J Neuroradiol. 2018;39(5):910-5.

25. Hassan T, Hassan AA, Ahmed YM. Influence of parent vessel dominancy on fluid dynamics of anterior communicating artery aneurysms. Acta Neurochir. 2011;153(2):305-10.

26. Rinaldo L, McCutcheon BA, Murphy ME, Bydon M, Rabinstein AA, Lanzino G Relationship of A1 segment hypoplasia to anterior communicating artery aneurysm morphology and risk factors for aneurysm formation. J Neurosurg. 2017;127(1):89-95.

27. Charbel FT, Seyfried D, Mehta B, Dujovny M, Ausman Jl. Dominant A1: angiographic and clinical correlations with anterior communicating artery aneurysms. Neurol Res. 1991;13(4):253-6.

28. Kerber CW, Imbesi SG, Knox K. Flow dynamics in a lethal anterior communicating artery aneurysm. AJNR Am J Neuroradiol. 1999;20(10):2000-3.

29. Karmonik C, Yen C, Grossman RG, Klucznik R, Benndorf G. Intra-aneurysmal flow patterns and wall shear stresses calculated with computational flow dynamics in an anterior communicating artery aneurysm depend on knowledge of patientspecific inflow rates. Acta Neurochir. 2009;151(5):479-85 discussion 85.

30. Cebral JR, Castro MA, Appanaboyina S, Putman CM, Millan D, Frangi AF. Efficient pipeline for image-based patient-specific analysis of cerebral aneurysm hemodynamics: technique and sensitivity. IEEE Trans Med Imaging. 2005;24(4):457-67.

31. Karmonik C, Yen C, Diaz O, Klucznik R, Grossman RG, Benndorf G. Temporal variations of wall shear stress parameters in intracranial aneurysms-importance of patient-specific inflow waveforms for CFD calculations. Acta Neurochir. 2010;152(8):1391-8 discussion 8.

32. Min JK, Taylor CA, Achenbach S, Koo BK, Leipsic J, Norgaard BL, et al. Noninvasive fractional flow reserve derived from coronary $C T$ angiography: clinical data and scientific principles. JACC Cardiovasc Imaging. 2015;8(10):1209-22.

33. Kaufmann P, Vassalli G, Lupi-Wagner S, Jenni R, Hess OM. Coronary artery dimensions in primary and secondary left ventricular hypertrophy. J Am Coll Cardiol. 1996;28(3):745-50.

34. Cebral JR, Castro MA, Putman CM, Alperin N. Flow-area relationship in internal carotid and vertebral arteries. Physiol Meas. 2008;29(5):585-94.

35. Smith T, Jafrancesco G, Surace G, Morshuis WJ, Tromp SC, Heijmen RH. A functional assessment of the circle of Willis before aortic arch surgery using transcranial Doppler. J Thorac Cardiovasc Surg. 2019;158(5):1298-304.

36. Scheel P, Ruge C, Petruch UR, Schoning M. Color duplex measurement of cerebral blood flow volume in healthy adults. Stroke. 2000;31(1):147-50.

\section{Publisher's Note}

Springer Nature remains neutral with regard to jurisdictional claims in published maps and institutional affiliations. 